\title{
PRESSURE MANAGEMENT BY COMBINING PRESSURE REDUCING VALVES AND PUMPS AS TURBINES FOR WATER LOSS REDUCTION AND ENERGY RECOVERY
}

\author{
S. PARRA \& S. KRAUSE \\ Sanitary Engineering and Waste Management, University of the Federal Armed Forces Munich, Germany.
}

\begin{abstract}
Conventional pressure reducing valves (PRVs) are often used in water distribution systems for pressure control and water loss reduction. Nevertheless, depending on the conditions in the network, advanced pressure management approaches might be more suitable. In this study, the potential water loss reduction for an intelligent system that combines PRVs and pumps as turbines (PATs) in a pilot study in Germany was estimated. The aim of the proposed system is to recover the pressure energy in the supply network by transforming it into electricity and, at the same time, contribute to the reduction of water losses and material stress. In order to evaluate the pressure situation and predict the water savings of the different pressure management strategies in the studied supply area, hydraulic modelling was used. Using the calibrated model, the optimal outlet pressure for the installed PRV and for the intelligent pressure control system was calculated, taking into account the pressure at the critical point as a boundary condition. Furthermore, the pressure-dependant leakage flow was simulated using the emitter coefficient feature in EPANET. Here, a pressure exponent of 1.5 was used, assuming uniform background leakage along the distribution system. For the analysed network, $28.5 \%$ and $45 \%$ water savings are expected for the fixed and for the advanced pressure management strategy, respectively. The predicted water savings and the leakage assumptions are to be verified either on field or experimentally. This study concludes that hydraulic modelling is essential for assessing water supply networks, as well as for optimizing current pressure management strategies and predicting its benefits.

Keywords: EPANET, hydraulic modelling, pressure management, pressure reducing valve, pump as turbine, water loss reduction.
\end{abstract}

\section{INTRODUCTION}

In the past 20 years an enhanced management of water and energy resources has been approached in the drinking water sector as well. Demographic and climate change and the aging supply networks are important drivers to be mentioned here. In Germany, as an industrialized nation, technologies for a more effective and economical energy use are being demanded nowadays. Examples are the optimization of the water distribution (i.e. pump operation) or the use of the surplus energy in the tank filling or in transport pipelines by using turbines or pumps as turbines (PATs) [1-3]. Despite this, the reduction of the water losses (which in Germany account in average for $7.6 \%$ of the water feeding volume [4]) and the adequate rehabilitation of the water networks are still the most important challenges for water supply companies.

In the past years, many authors have analysed in several publications the relationship between leakage and pressure within water distribution systems [5-8]. It is well known that the management of the pressure in the network in combination with an optimal repairing and rehabilitation planning plus an active leakage control, are the fundamentals of an effective 
strategy to curtail water loss [6]. For controlling the pressure in the network, preventing water stress in pipelines and armatures and avoiding new bursts in the grid, pressure reducing valves (PRVs) are commonly used. Conventional fixed outlet PRVs reduce the inlet pressure $\left(\mathrm{p}_{\text {in }}\right)$ to a defined value $\left(\mathrm{p}_{\text {out }}\right)$ and deliver a constant operational pressure, independent of the water demand [9]. For an enhanced pressure management, more advanced technologies, socalled time-modulated (a), flow-modulated (b) or remote-controlled (c) pressure control devices can be installed. The main idea here is to reduce the pressure (a) depending on day time and off-peak periods, (b) on the water consumption and (c) on the actual pressure at one or multiple critical points within the supply area $[10,11]$. The decision whether to apply conventional PRVs or an advanced pressure management device depends strongly on the conditions within the supply area, like the amount of water losses, the available personnel, the investment costs and so on.

In this study, the water loss reduction in a pilot study area in northern Germany was estimated for a fixed-outlet and for an advanced (remote-controlled) pressure management. For this, the optimum pressure values were determined using hydraulic modelling in EPANET 2.0 [12]. The amount of water loss that is dependant on the operational pressure in the network was assessed using the emitter coefficient in the calibrated model, as proposed by Walski and Karadirek [13, 14]. The findings of this study may serve as a decision support for the implementation of pressure management strategies in water distribution systems, like conventional PRVs or more advanced systems (i.e. PATs for additional energy recovery). This study took place in the frame of the research project EWID (abbreviation in German for "Energy recovery in the water distribution system by intelligent pressure management"), where PATs take over the function of PRVs, with the aim of recovering the pressure energy in the supply network by transforming it into electricity [15]. The proposed system is composed of a pressure control unit (PRV) plus an energy production unit (PAT) located in the bypass, and a control unit for an intelligent pressure management. The goal here is to maximize the energy production and at the same time to develop a remote-demand-based pressure management. Currently, the energy recovery is evaluated within a small-scale test stand developed for this purpose at the University of the Federal Armed Forces Munich. The research project EWID is sponsored by the German Federal Ministry of Education and Research in the framework of the program Future-oriented Technologies and Concepts for an Energy-efficient and Resourcesaving Water Management - ERWAS. The project started on April 2014 and ends on March 2017.

\section{METHODOLOGY}

\subsection{Case study}

The analysed supply area, with 1,200 inhabitants and 940 service connections, is located in a rural area in northern Germany. The water distribution system as shown in Fig. 1 comprises $27 \mathrm{~km}$ water pipelines (without service connections) mainly of PVC and cast iron. Characteristic of the area are its high elevation differences, starting from $401.0 \mathrm{~m}$ at the feeding tank (tank 1), up to $155.0 \mathrm{~m}$ at the lowest point in the supply area (at village D). For avoiding high operational pressures in the system, two PRVs are installed in the villages A and $\mathrm{B}$, respectively. Due to the hydraulic and geodetic situation, the system is divided into 4 pressure areas. The water supply company selected the PRV 1 for implementing the 


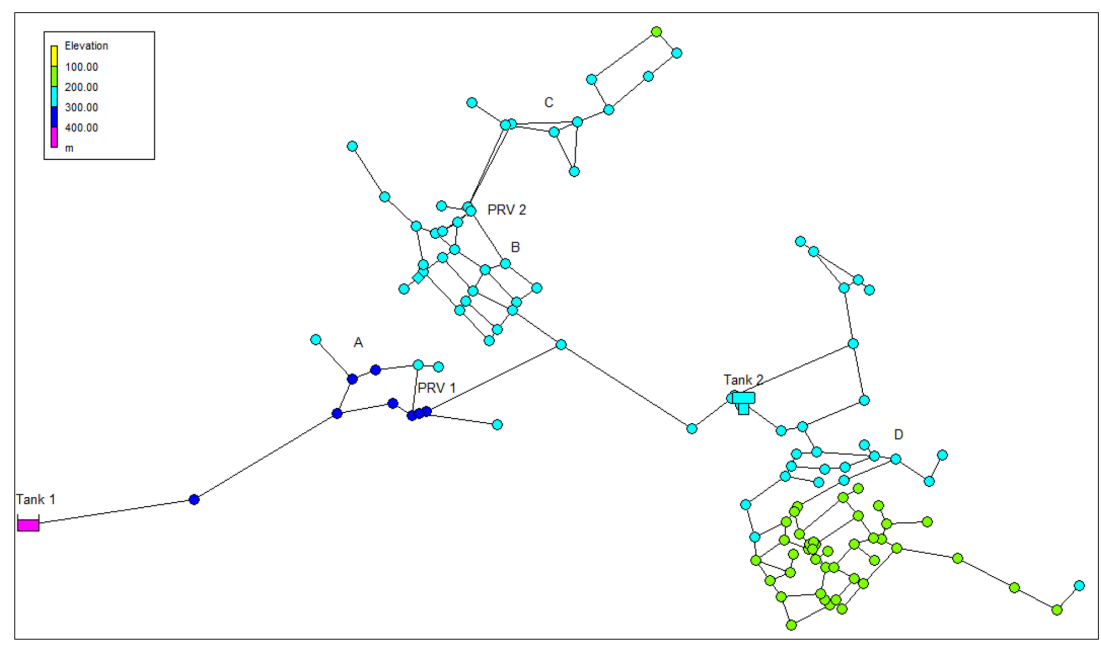

Figure 1: Analysed drinking water distribution system for the case study.

PAT-system proposed by EWID, in order to improve the pressure management and the energy efficiency in the system.

In order to analyse the water balance in the network, the supply area was divided into two district metered areas (DMA) with the storage tank 2 as the boundary between DMA 1 and DMA 2. On June 2015, the water outflow from tank $1 \mathrm{Q}_{\mathrm{T} 1}$ and the inlet and outlet pressures at PRV $1\left(\mathrm{p}_{\text {in }}\right.$ and $\left.\mathrm{p}_{\text {out }}\right)$ were recorded for evaluating the flow and pressure parameters in DMA 1(see Fig. 2).

Furthermore, $\mathrm{Q}_{\mathrm{T} 1}$ and the minimum night flow $\mathrm{Q}_{\mathrm{MNF}}$ were used for estimating the water losses, as no water balance data was available for the complete distribution system. Here, the water volume lost due to physical leakages in mains, storage tanks and service connections (defined as real water losses, $\mathrm{Q}_{\mathrm{RL}}$ ) was derived from the measured data as recommended by the German Technical and Scientific Association for Gas and Water (DVGW):

$$
\begin{aligned}
Q_{\mathrm{RL}} & =Q_{M N F}-Q_{\text {rest }} \\
q_{\mathrm{RL}} & =\frac{Q_{R L}}{L_{N}}
\end{aligned}
$$

with $\mathrm{Q}_{\mathrm{RL}}=$ real water losses, $\mathrm{Q}_{\mathrm{MNF}}=$ minimum night flow, $\mathrm{Q}_{\text {rest }}=$ rest water consumption = $0.6-0.8 \mathrm{~m}^{3} / \mathrm{h}$ per 1,000 inhabitants, $\mathrm{q}_{\mathrm{RL}}=$ specific real water losses and $\mathrm{L}_{\mathrm{N}}=$ network length without service connections [16]. The calculated specific real water loss $q_{R L}$ of $0.12 \mathrm{~m}^{3} /(\mathrm{h} * \mathrm{~km})$ correlates with the estimation provided by the water supply company and comprises $80 \%-85 \%$ of the minimum night flow. According to German reference values, the water loss volume is high for typical rural regions [16].

\subsection{Hydraulic modelling}

EPANET 2.0 was used to analyse the hydraulic situation in the studied supply area and for predicting the potential water loss reduction by implementing an advanced pressure 


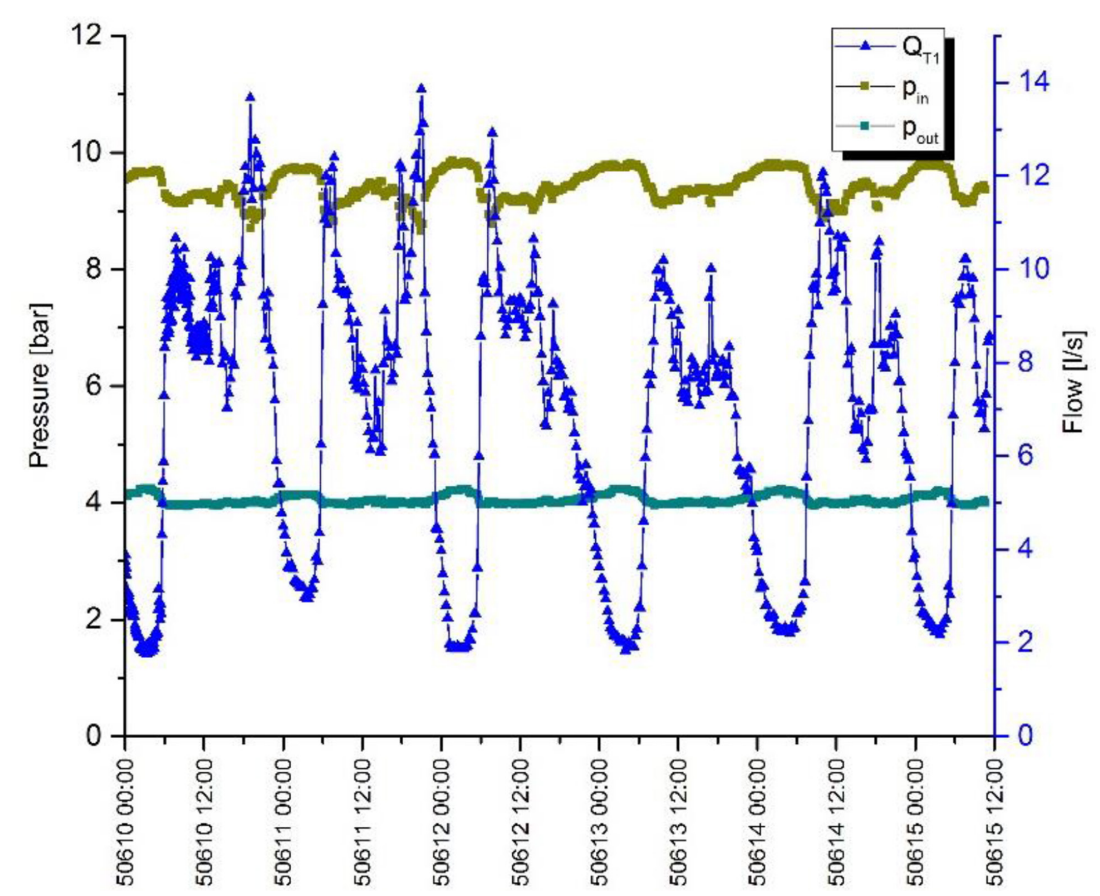

Figure 2: Example of recorded outflow from tank $1\left(\mathrm{Q}_{\mathrm{T} 1}\right)$ and inlet and outlet pressures at PRV $1\left(\mathrm{p}_{\text {in }}\right.$ and $\left.\mathrm{p}_{\text {out }}\right)$.

management at PRV 1, as chosen by the water supply company. The input data required for running the dynamic model comprised the following:

(a) Water network data from the Geographic Information System provided by the water supply company. It included the configuration of links (pipelines) and nodes (storage tanks, PRVs, etc.), including diameters, materials, elevations and other attributes.

(b) The water outflow from tank 1 and tank 2 recorded on June 2015, which was used for creating a characteristic pattern for the domestic consumption (see example in Fig. 3). For this, the data were filtered for removing outliers due to planned flush events. Subsequently, the flow values were averaged for every hour of the day, considering working and weekend days separately. Industrial consumers (e.g. paper factory at village D) were considered individually.

(c) The annual billed water consumption per village.

(d) The estimated amount of water losses $Q_{R L}$.

After the hydraulic model was established, the calibration of the model was performed by comparing the modelled and measured data, according to the DVGW [17]. For this, the pressure and the water inflow of each village were recorded using data loggers at strategic nodes in the network during two days. The aim here was to find the correct friction coefficient of the pipelines and to verify the input data. The model calibration included the performance of two artificial flush events with about $50 \mathrm{~m}^{3} / \mathrm{h}$ in order to verify the head loss at the selected nodes 


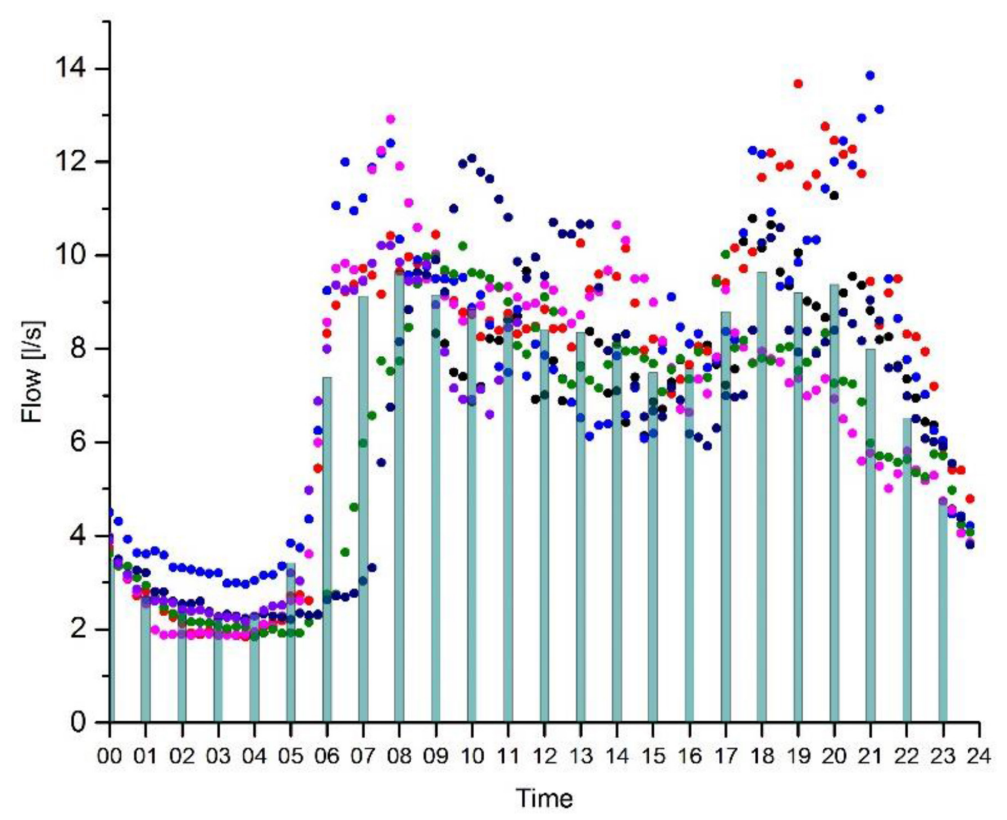

Figure 3: Characteristic pattern of domestic demand for hydraulic modelling.

for steady-state conditions. The pipe roughness was adjusted by trial and error until a maximum mean error of $2 \mathrm{~m}$ for the pressure heads was achieved.

\subsection{Leakage modelling}

With the aim of predicting the potential water loss reduction by improving the pressure management in the studied supply area, the amount of water losses was modelled in EPANET, for a fixed outlet pressure control (conventional PRV) and an advanced pressure management (critical point approach). For this purpose, the flow emitter was used for modelling the relationship pressure - leakage, as recommended by Walski and Karadirek [13, 14]. Here, the flow rate $\mathrm{Q}$ through an orifice is described as a function of the pressure in the node as:

$$
\mathrm{Q}=C P^{\gamma}
$$

with $\mathrm{C}=$ leakage coefficient, $\mathrm{P}=$ nodal pressure and $\gamma=$ pressure exponent. In EPANET, the pressure exponent $\gamma$ is defined with the default value of 0.5 , appropriate for modelling nozzles and sprinklers. Nevertheless, for modelling leakages, a higher value might be more suitable, as reported by many authors in publications and field studies on leaks in water distribution systems in different countries $[6,8,18]$. The authors conclude that $\gamma$ varies from 0.5 to 2.5 , depending on the pipe material and the orifice area and suggest, that undetectable background leaks show higher pressure exponents than reported pipe bursts. For background leakage, a value of 1.5 is usually applied, as the leakage area expands proportionally with an increase in pressure [18]. In the present study, a mean value of 1.5 was chosen. This value was estimated taking the pipe material - mainly PVC - into account and assuming mostly the background leakage uniformly distributed along the supply area. For simplifying the leak modelling, the leakage was placed at a single node located at an average elevation in the DMA. 


\section{RESULTS}

\subsection{Critical point and optimal outlet pressure for PRV 1}

The calibrated hydraulic model was used for evaluating the temporal and spatial changes of water pressure and flow in the studied water distribution system. At first, the current situation in DMA 1 was analysed to identify the critical point in the area. In general, depending on the topography of the water system, the critical point might be defined as:

- the point, where the operational pressure might fall below the minimal value more likely, for instance, the highest points in the network; or

- the point, where the resting pressure might exceed the maximum value more likely, for instance, the lowest point in the network.

Due to the topography in the studied pilot area, the critical point was identified as the lowest point in the system, at node 141 in village B. At this point, a resting pressure of 8 bar must not be exceeded for preventing material stress and increased abrasion in the pipelines and armatures [19].

Subsequently, for evaluating the impact of pressure management at PRV 1, the pressure at the critical point was simulated for:

a. The current situation, with an outlet pressure $\mathrm{p}_{\text {out }}$ of 4.0 bar.

b. An enhanced fixed outlet strategy, with an outlet pressure $\mathrm{p}_{\text {out }}$ of $2.0 \mathrm{bar}$.

c. An advanced pressure management (critical point approach, remote controlled). For this, the optimal outlet pressure curve $\left(\mathrm{p}_{\text {out-dyn }}\right)$ was calculated using the calibrated model, for achieving a constant pressure of 8 bar at the node 141 at every hour of the day. The dynamic outlet pressure curve was implemented using the CONTROLS feature in EPANET.

The results for the simulations a, b and c are presented in Fig. 4.

\subsection{Water loss reduction due to pressure management}

In order to compare the different pressure management strategies regarding the water savings, the current real water loss $\mathrm{Q}_{\mathrm{RL}}(0.50 \mathrm{l} / \mathrm{s})$ was simulated using the emitter coefficient in EPANET. Later, the pressure dependant leakage flow was determined by comparing the water inflow in DMA 1 for the fixed outlet and for the advanced pressure management approach. The results are presented in Table 1.

As shown in Table 1, high water savings can be achieved in DMA 1 for both applied pressure management strategies, when assuming all real water losses as background leakages (pressure exponent of 1.5). Furthermore, by implementing an advanced approach (critical point approach, remote controlled) additional water savings of $16.5 \%$ are expected.

Regarding the costs of the different approaches, the application of advanced pressure management strategies must be well thought of. For this, it is essential to previously assess and evaluate each DMA in detail. In general, the implementation of intelligent pressure management strategies will be feasible in supply networks with large differences between night and daytime water demands. In areas with low consumption differences, the additional savings might be marginal [20].

In this study case, the proposed advanced pressure system is composed of a pressure control unit plus an energy production unit located in the bypass, and a control unit for an 


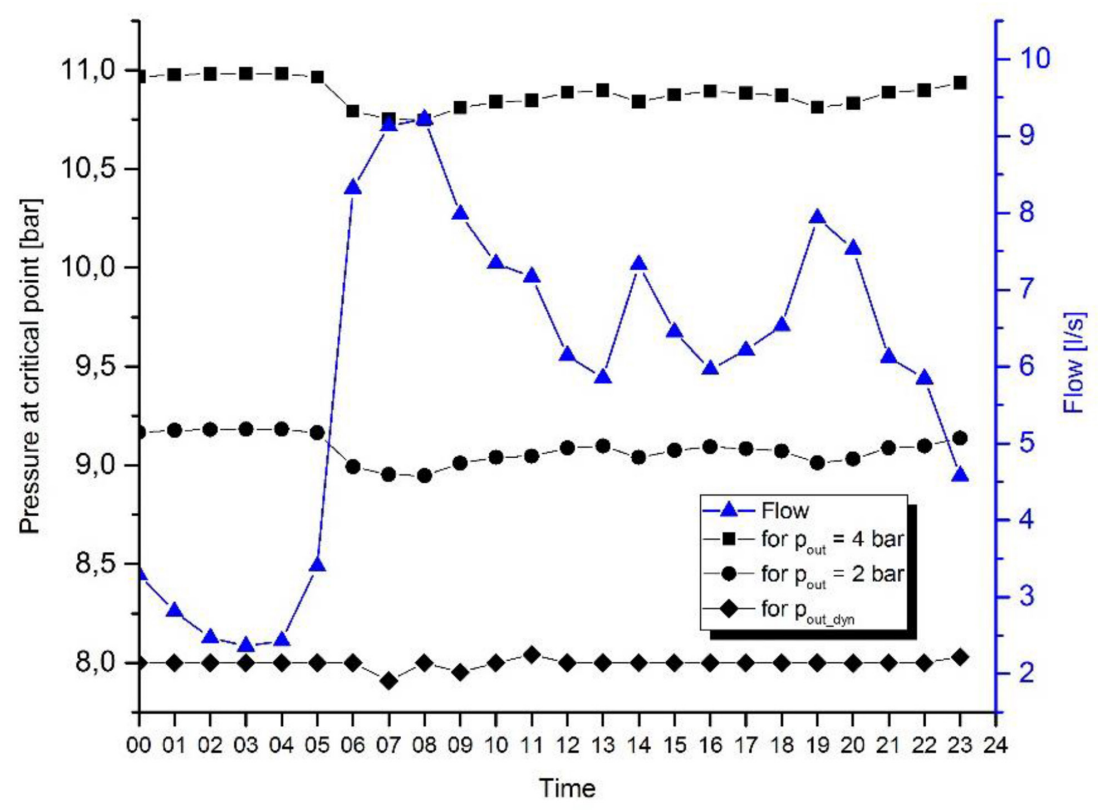

Figure 4: Pressure at critical point of DMA 1 (node 141) for the current situation $\left(\mathrm{p}_{\text {out }}=4.0\right.$ bar) and an enhanced pressure management $\left(\mathrm{p}_{\text {out }}=4.0\right.$ bar and $\left.\mathrm{p}_{\text {out_dyn }}\right)$.

Table 1: Summary of predicted pressures and water loss savings in DMA 1 determined by hydraulic modelling and leak simulation (with 1.5 as pressure exponent).

\begin{tabular}{llll}
\hline & current PRV & $\begin{array}{c}\text { enhanced fixed } \\
\text { outlet PRV }\end{array}$ & $\begin{array}{c}\text { advanced pressure } \\
\text { management }\end{array}$ \\
\hline Outlet pressure PRV 1 & $4 \mathrm{bar}$ & $2 \mathrm{bar}$ & $0.8-1 \mathrm{bar}$ \\
Mean pressure at critical point & $10.9 \mathrm{bar}$ & $9.1 \mathrm{bar}$ & $8.0 \mathrm{bar}$ \\
Real water losses $\mathrm{Q}_{\mathrm{RL}}$ & $0.50 \mathrm{l} / \mathrm{s}$ & $0.36 \mathrm{l} / \mathrm{s}$ & $0.28 \mathrm{l} / \mathrm{s}$ \\
Water loss reduction $\Delta \mathrm{Q}_{\mathrm{RL}}$ & & $0.14 \mathrm{l} / \mathrm{s}$ & $0.22 \mathrm{l} / \mathrm{s}$ \\
& & $4,500 \mathrm{~m}^{3} / \mathrm{a}$ & $7,000 \mathrm{~m}^{3} / \mathrm{a}$ \\
Water loss reduction in $\%$ & & $28.5 \%$ & $45 \%$ \\
\hline
\end{tabular}

intelligent pressure management. The goal here is to maximize the energy production and at the same time to develop a demand-based pressure management system. This will ensure that the benefits do not rely not just on the reduction of the water losses and the material stress in the water distribution network. The main goal of the EWID system is the overall improvement of the energy efficiency in the network.

\section{CONCLUSIONS}

Pressure management might be very important in water distribution systems with high differences in altitude (e.g. mountainous regions), especially in networks with high operational 
pressures. A maximal resting pressure value of 8 bar, recommended by the DVGW [19], should not be exceeded in order to reduce material stress and prevent new pipe bursts. In some cases, the further reduction of the outlet pressure of conventional PRVs should be reconsidered, in order to alleviate the water network and reduce the water losses additionally. Moreover, the implementation of advanced pressure management strategies should be weighed up, considering both the benefits and the investment costs. Here, depending on the boundary conditions of the water network and the leak type, water savings up to $45 \%$ can be achieved.

As proposed by EWID, in addition to the water loss reduction, the energy recovery by complementing PRVs with pumps as turbines, might be an attractive option for some water supply networks. The goal here is to combine energy recovery and advanced pressure management, taking the real time conditions within the supply area (critical-point-modulation) into account. At the moment, extensive testing is being carried out on a small-scale test stand at the University of the Federal Armed Forces Munich. The testing facilities were designed according to the boundary conditions of two selected supply networks in Germany, where the developed system will be installed, optimized and calibrated for continuous operation later on. Preliminary results estimate up to $5 \mathrm{~kW}$ energy recovery with a system payback period of $8-11$ years, assuming a mean flow of $7-8$ 1/s and $85 \mathrm{~m}$ pressure reduction [15].

In this study it was confirmed that pressure management is crucial for reducing water loss from background leakage. While big leakages and pipe bursts might be reported quickly, undetectable background leakage might cause high water loss volumes as it cannot be detected and reported on time (long runtime!). However, pressure management cannot be regarded as the unique approach for water loss reduction. Here, strategic rehabilitation planning, considering the actual status/condition of the water network, should be the priority for water supply companies.

Hydraulic modelling is an essential tool for understanding the relationship between flow and pressure in water distribution systems. In this study, the critical points were identified and the optimal pressure requirements (e.g. optimal outlet pressure curve for PRV 1) were determined using EPANET. Afterwards, using the calibrated model, the water leakages were simulated in order to estimate the water savings by implementing different pressure management strategies. Nevertheless, it must be mentioned that leak modelling requires a high expertise with respect to the pressure coefficients and exponents shown in eqn (3). The leak flow and, therefore, the water savings are very sensitive to the applied pressure exponent $\gamma$. Furthermore, as already reported by Lambert, the flow conditions (laminar or turbulent) have a high influence in the leak flow [6]. For this, a detailed experimental validation or a further verification of leakage modelling in field studies is needed.

\section{REFERENCES}

[1] Haakh, F., Holmer, F. \& Nill, A., Energieeffizienz in der Fernwasserversorgung am Beispiel der Landeswasserversorgung. Beitrag 5, LW-Schriftenreihe 2013, 54-66, 2013.

[2] Kramer, M. \& Wieprecht, S., Untersuchungen zum Einsatz von Kleinturbinen in der Trinkwasserversorgung. In wat+gat (spezial) Tagungsband 2, 2012.

[3] Sitzenfrei, R., Berger, D. \& Rauch, W., Design and optimization of small hydropower systems in water distribution networks under consideration of rehabilitation measures.

Urban Water Journal, pp. 1-9, 2015.

http://dx.doi.org/10.1080/1573062X.2015.1112410 
[4] Statista, Wasserverluste in der öffentlichen Wasserversorgung in Deutschland von 1999 bis 2013, available at: http://de.statista.com/statistik/daten/studie/155684/umfrage/wasserverluste-in-der-oeffentlichen-wasserversorgung-seit-1991/ (accessed 20 April 2016).

[5] Gomes, R., Sousa, J. \& Marques, A.S., The influence of pressure/leakage relationships from existing leaks in the benefits yielded by pressure management. Water Utility Journal, 5, pp. 25-32, 2013.

[6] Lambert, A., What do we know about pressure-leakage relationships in distribution systems? In System Approach to Leakage Control and Water Distribution Systems Management. IWA International Specialised Conference, 2001.

[7] McKenzie, R., Mostert, H. \& Jager, T., Leakage reduction through pressure management in Khayelitsha: Two years down the line. In Biennial Conference and Exhibition of the Water Institute of Southern Africa, Water Institute of Southern Africa, 2004.

[8] Schwaller, J. \& van Zyl, J.E., Modeling the pressure-leakage response of water distribution systems based on individual leak behavior. Journal of Hydraulic Engineering, 141(5), 4014089, 2015. http://dx.doi.org/10.1061/(ASCE)HY.1943-7900.0000984

[9] DVGW, Merkblatt W 335: Druck-, Durchfluss- und Niveauregelung in Wassertransport und -verteilung. Wirtschafts- u. Verlagsges. Gas u. Wasser, Bonn, 2000.

[10] Deutsche Gesellschaft für Internationale Zusammenarbeit \& VAG Armaturen GmbH, Guidelines for water loss reduction. A focus on pressure management, 2011.

[11] McKenzie, R. \& Wegelin, W., Implementation of pressure management in municipal water supply systems. IWA Water Press, 0309, 2009.

[12] Rossman, L., EPANET 2, Users Manual, 2000.

[13] Karadirek, I.E., Kara, S., Yilmaz, G., Muhammetoglu, A. \& Muhammetoglu, H., Implementation of hydraulic modelling for water-loss reduction through pressure management. Water Resources Management, 9, 2012.

[14] Walski, T., Chase, D., Savic, D., Grayman, W., Beckwith, S. \& Koelle, E., Advanced Water Distribution Modeling and Management, Bentley Institute Press, Exton, PA, 2003.

[15] Parra, S., Krönlein, F., Krause, S. \& Günthert, W., Energiegewinnung imWasserverteilungsnetz durch intelligentesDruckmanagement - EWID, energie | wasser-praxis, 12, 2015.

[16] DVGW, Arbeitsblatt W 392: Wasserverlust in Rohrnetzen - Ermittlung, Überwachung, Bewertung, Wasserbilanz, Kennzahlen. Wirtschafts- u. Verlagsges. Gas u. Wasser, Bonn, 2003.

[17] DVGW, Arbeitsblatt GW 303-1: Berechnung von Gas- und Wasserrohrnetzen - Teil 1: Hydraulische Grundlagen, Netzmodellierung und Berechnung. Wirtschafts- $u$. Verlagsges. Gas u. Wasser, Bonn, 2006.

[18] Ulanicki, B., Bounds, P., Rance, J.P. \& Reynolds, L., Open and closed loop pressure control for leakage reduction. Urban Water, 2(2), pp. 105-114, 2000. http://dx.doi.org/10.1016/S1462-0758(00)00048-0

[19] DVGW, Arbeitsblatt W 400-1: Technische Regeln Wasserverteilungsanlagen (TRWV); Teil 1: Planung Oktober 2004. Wirtschafts- u. Verlagsges. Gas u. Wasser, Bonn, 2004.

[20] Hamilton, S. \& McKenzie, R.S., Water Management and Water Loss, IWA Publishing: London, UK, 2014. 